\title{
A RELAÇÃO DO PULSO DE INUNDAÇÃO COM A REPRODUÇÃO DE Hoplias malabaricus (BLOCH, 1794) (CHARACIFORMES, ERYTHRINIDAE) NO SISTEMA DAS BAÍAS CAIÇARA DO PANTANAL NORTE, ESTADO DE MATO GROSSO, BRASIL
}

\author{
THE FLOOD PULSE AND ITS RELATIONSHIP WITH \\ REPRODUCTION OF Hoplias malabaricus (BLOCH, 1794) \\ (CHARACIFORMES, ERYTHRINIDAE) IN THE \\ CAIÇARA BAYS SYSTEM, NORTH PANTANAL, MATO \\ GROSSO STATE, BRAZIL
}

\section{Jéssica Rodrigues de Oliveira; Ernandes Sobreira Oliveira Junior; Claumir César Muniz}

Laboratório de Ictiologia do Pantanal Norte, Universidade do Estado de Mato Grosso.

Email jessicarodrigues-91@hotmail.com; ernandes.biodagua@yahoo.com.br; claumir@unemat.br

\begin{abstract}
RESUMO
Este trabalho teve como objetivo estudar a reprodução de Hoplias malabaricus (traíra) em um sistema de baías do Pantanal Norte, em Mato Grosso que mantêm conexão com o rio Paraguai durante os períodos hidrológicos distintos deste complexo, descrevendo os padrões sazonais de desova da espécie. Foram estudados 380 indivíduos capturados com tela de material plástico, rede de arrasto e tarrafas de diferentes malhagens e alturas entre setembro de 2005 a setembro de 2007, englobando os diferentes períodos sazonais pantaneiros. O material biológico foi fixado em formalina a $4 \%$ por 72 horas e conservado em solução de álcool $70 \%$ e verificado seu comprimento padrão (Ls), peso total $(\mathrm{Wt})$ e determinado o sexo e estádio de maturação gonadal. $\mathrm{O}$ início da reprodução ocorreu no período de enchente, se estendendo até o período de cheia, época com maior volume de água. Os meses com maior abundância coincidiram com período da estiagem e predomínio de indivíduos adultos machos. Peixes de vários comprimentos foram capturados, indicando que as baías marginais do rio Paraguai apresentam condições favoráveis ao desenvolvimento desta espécie.

Palavras-chave: Períodos Sazonais. Estádio Reprodutivo. Hoplias malabaricus. Baias Marginais.
\end{abstract}

\section{ABSTRACT}

This work had as objective to study the reproductive aspect of Hoplias malabaricus (traíra) in the Caiçara bays system, North Pantanal, state of Mato Grosso; establishing the seasonal standards of spawning of this fish species. Were captured 380 individuals with a mesh made by plastic material, net of drag and casting nets of different sizes and heights between September of 2005 to September 
of 2007 , in the different seasonal period. After collected, they was fixed in formalin $4 \%$ for 72 hours and conserved in alcohol solution with $70 \%$ and verified its length standard (Ls), total weight (Wt), sexed and analyzed the stadium of gonadal maturation. The beginning of the reproduction occurred in the flood period, extending until the full period, time with bigger volume of water in the studied environment. The months with higher abundance had coincided with dry period, having also had predominance of adult and male individuals. Fishes of various lengths had been captured, indicating that the marginal lake of the main channel of the river presents conditions favorable to the development of this species.

Key words: Seasonal periods. Reproductive Stadium. Hoplias malabaricus. Marginal bays.

\section{INTRODUÇÃO}

O pantanal é formado pela interação das planícies de inundação de toda a malha hidrográfica da Bacia do Alto Paraguai-BAP. Esta região é a maior planície contínua de inundação do planeta, regida por um período de chuvas, com superfície aproximada de $140 \mathrm{mil} \mathrm{km}^{2}$ (CALHEIROS e OLIVEIRA, 2010). A dinâmica das águas é caracterizada por chuvas entre os meses de novembro a março e nos meses de julho a setembro observa-se uma redução na quantidade de água no sistema hidrológico.

$\mathrm{Na}$ maioria, os lagos, baías e corixos na área pantaneira possuem uma profundidade pequena, raramente ultrapassando os dois metros, o que torna esses corpos de água suscetíveis às alterações de temperatura, oxigênio dissolvido, matéria orgânica, $\mathrm{pH}$ e salinidade, principalmente durante o período de vazante/seca, interagindo de forma direta na comunidade aquática local (MUNIZ, 2010).

Nesse ambiente dinâmico, regido por um sistema de cheias e estiagens, se encontra uma ictiofauna rica e diversificada e uma abundante comunidade animal dependente de peixes para sua sobrevivência (RESENDE, 2008).

O Pantanal, em seu complexo hidrodinâmico apresenta flutuações sazonais, em que a maioria das espécies de peixes exibe uma estratégia de reprodução, explorando a variação temporal e espacial dos ambientes com o objetivo de aumentar a sobrevivência e crescimento de juvenis (WINEMILLER, 1989).

Descrito por Britski et al. (2007) com 269 espécies das mais variadas funções ecossistêmicas, o Pantanal é explorado pela pesca de espécies como o Pacu (Piaractus mesopotamicus) e Pintado (Pseudoplatistoma corruscans), além de outras com menor foco para pesca, porém importante fonte de energia para ribeirinhos, pelo alto valor nutricional de sua carne (TORRES et al., 2012) e presente em pratos típicos da região, como no caso da Traíra (Hoplias malabaricus).

A Traíra, espécie abundante no Pantanal, comum em ambientes lênticos e semi-lóticos (UIEDA, 1984), é capaz de desenvolver todo o seu ciclo de vida dentro de uma área geográfica relativamente pequena (BIALETZKI et al., 2002) e apresenta características ecológicas de alta resistência a modificações ambientais.

Esta espécie abrange quase todas as bacias hidrográficas da América do Sul apresentando características ecológicas adaptadas a cada região (FOWLER, 1950), tendo corpo alongado e grosso, língua áspera, provida de dentículos. Dorso e lados do corpo com manchas ou barras irregulares inclinadas, ás vezes em forma de "V" com o vértice para frente; cabeça com três listras atrás dos olhos, nem sempre bem visíveis. Todas as nadadeiras com pontos escuros; às vezes ordenados formando faixas; e comprimento máximo de $500 \mathrm{~mm}$ (BRITSKI et al., 2007).

Por apresentar comportamento sedentário (CARAMASCHI, 1979), e características adaptativas as modificações ambientais (MARQUEZ et al., 2001), a traíra pode funcionar como 
ferramenta na obtenção de dados para o manejo ecológico e conservação do Pantanal, principalmente no que tange aspectos ecológicos referentes à dieta e reprodução.

A reprodução desta espécie foi estudada em rios e reservatórios de várias regiões da América do Sul (VAZZOLER e MENEZES, 1992), e a desova é caracterizada por ocorrer de forma parcelada, além de manter cuidado com a prole (ARAÚJO-LIMA e BITENCOURT, 2001), porém, pouco se sabe sobre seu aspecto reprodutivo no Pantanal Norte, em que se acredita que a dinâmica do pulso de inundação pode influenciar na reprodução desta espécie durante as distintas características ambientais.

O objetivo deste trabalho foi caracterizar a reprodução de $H$. malabaricus, de acordo com a sazonalidade hídrica de baías marginais ao rio Paraguai, próximas a cidade de Cáceres-MT.

\section{MATERIAL E MÉTODOS}

\section{1. Área de estudo}

A área estudada é descrita como um sistema de Baías que se conectam em períodos de águas altas no Pantanal, enquanto que permanecem desconectadas em períodos de estiagem, descritas como Sistema de Baías Caiçara, termo este usado para referenciar sua plasticidade morfológica e ambiental. As Baías localizam-se próximas à cidade de Cáceres, na margem direita do rio Paraguai

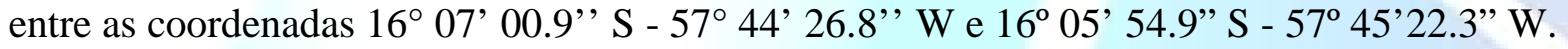

O Sistema de Baías Caiçara é composto por inúmeras baías formadas pela inundação lateral. No período de cheia apresentam-se praticamente como um corpo de água único de características semi-lóticas, sendo conectado lateralmente à outras baías e ao rio Paraguai. Durante o período de estiagem, todavia, ela se apresenta em duas porções, classificadas neste trabalho de subsistemas, denominadas de Baía Caiçara Superior (BCS) e Baía Caiçara Inferior (BCI) (Figura 1). A Baía Caiçara Inferior mantém conexão com o rio Paraguai e com baías vizinhas, tanto no período de águas cheias quanto baixas. Já o sistema de Baía Caiçara Superior (BCS), no período de estiagem é desconectado lateralmente de outras baías e do rio Paraguai.

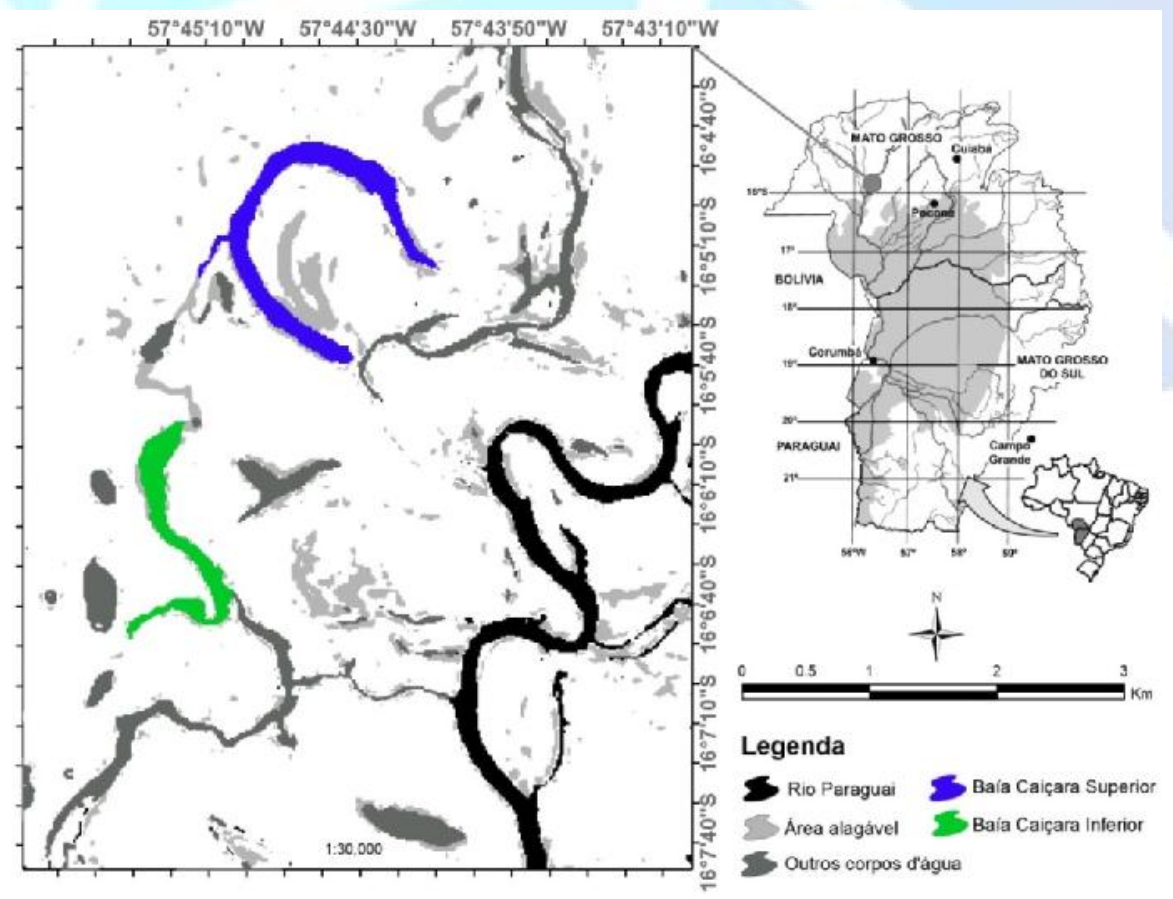

Figura 1. Localização do Sistema de Baías Caiçara, Pantanal Norte, Cáceres-MT. Fonte:.Wilkinson Lopes Lázaro (2013). 


\subsection{Coleta dos dados}

O trabalho foi realizado com exemplares de peixes coletados bimestralmente de setembro de 2005 a setembro de 2007, compreendendo os quatro períodos sazonais característicos do ambiente pantaneiro (enchente, cheia, vazante e estiagem).

Para a captura de peixes associados às macrófitas aquáticas, no sistema de baías, foi utilizada tela de material plástico, tipo mosquiteiro, armada em estrutura metálica com $105 \mathrm{~cm} \mathrm{x}$ $205 \mathrm{~cm}$ x $100 \mathrm{~cm}$, em tréplicas passadas sob os camalotes.

Os peixes de áreas abertas foram capturados com rede de arrasto e com malhas de 2, 3, 4, 5 e $6 \mathrm{~cm}$ entre nós com dimensões de $35 \mathrm{~m}$ x 2,2 m. Para ambientes mais profundos (ou períodos de cheia) foi utilizado tarrafas de diferentes malhagens e alturas (tarrafas de malhas 2 e $3 \mathrm{~cm}$ nas áreas de meandros).

Os peixes capturados foram fixados em formalina a $4 \%$ por 72 horas e conservados em solução de álcool 70\%. No laboratório de Zoologia da Universidade do Estado de Mato Grosso UNEMAT, Campus de Cáceres, foram verificados seu comprimento padrão (Ls), peso total (Wt), sexo e estádio de maturação gonadal, conforme descrito por Vazzoler (1996).

A determinação do Índice Gonadossomático (IGS) foi realizado de acordo com Vazzoler (1996) em que IGS=Wg/Wt.100, sendo $\mathrm{Wg}$ = peso da gônada e $\mathrm{Wt}=$ peso total do peixe.

\section{RESULTADOS E DISCUSSÃO}

Foram capturados 380 exemplares de H. malabaricus, sendo 222 da Baía Caiçara Superior (BCS) e 158 da Baía Caiçara Inferior (BCI). Estes dados podem estar relacionados ao fato de que a $\mathrm{BCS}$, no período de estiagem, permanece isolada lateralmente de outras baías e do rio Paraguai, enquanto BCI mantém conectada, tanto no período de águas altas quanto baixas.

Segundo Junk (1999), a conectividade funciona como rota de migração, dispersão e refúgio para os organismos aquáticos durante o período de estiagem, além do que no período das águas altas estes peixes dispersam-se pelo ambiente, o qual possui maior área, dificultando sua captura.

O período com maior frequência de $H$. malabaricus em todo o sistema de baías foi apresentado na estiagem $(n=285)$, sendo que no período de cheia $(n=7)$ ocorreu o menor número de indivíduos coletados.

Através da análise macroscópica das gônadas, foram identificados 140 machos e 82 fêmeas em BCS, enquanto em BCI foram 91 machos e 67 fêmeas distribuídos com seus aspectos reprodutivos de acordo com a Tabela 1.

Tabela 1 - Descrição dos indivíduos capturados de acordo com os períodos hidrológicos e locais de amostragem.

\begin{tabular}{cccccccccc}
\hline Estádio Gonadal & \multicolumn{2}{c}{ Enchente } & \multicolumn{2}{c}{ Cheia } & \multicolumn{2}{c}{ Vazante } & \multicolumn{2}{c}{ Estiagem } \\
& BCS & BCI & BCS & BCI & BCS & BCI & BCS & BCI & Total \\
Imaturo & 0 & 2 & 1 & 1 & 1 & 1 & 3 & 9 & 18 \\
Em Maturação & 35 & 13 & 0 & 0 & 0 & 3 & 5 & 11 & 67 \\
Maturo & 4 & 4 & 3 & 1 & 2 & 0 & 0 & 0 & 14 \\
Repouso & 2 & 0 & 0 & 1 & 11 & 7 & 155 & 102 & 278 \\
Total & 41 & 19 & 4 & 3 & 14 & 11 & 163 & 122 & $\mathbf{3 7 7}$ \\
\hline
\end{tabular}


No período de estiagem foram encontrados maiores valores de frequência de ocorrência de H. malabaricus em estádio reprodutivo de Repouso, enquanto o período de Cheia foram observadas maiores frequências de indivíduos de H. malabaricus em período reprodutivo Maturos (Figura 2). Pode-se perceber que há uma flutuação na dinâmica reprodutiva de $H$. malabaricus, mantendo relação com os períodos hidrológicos do Pantanal.

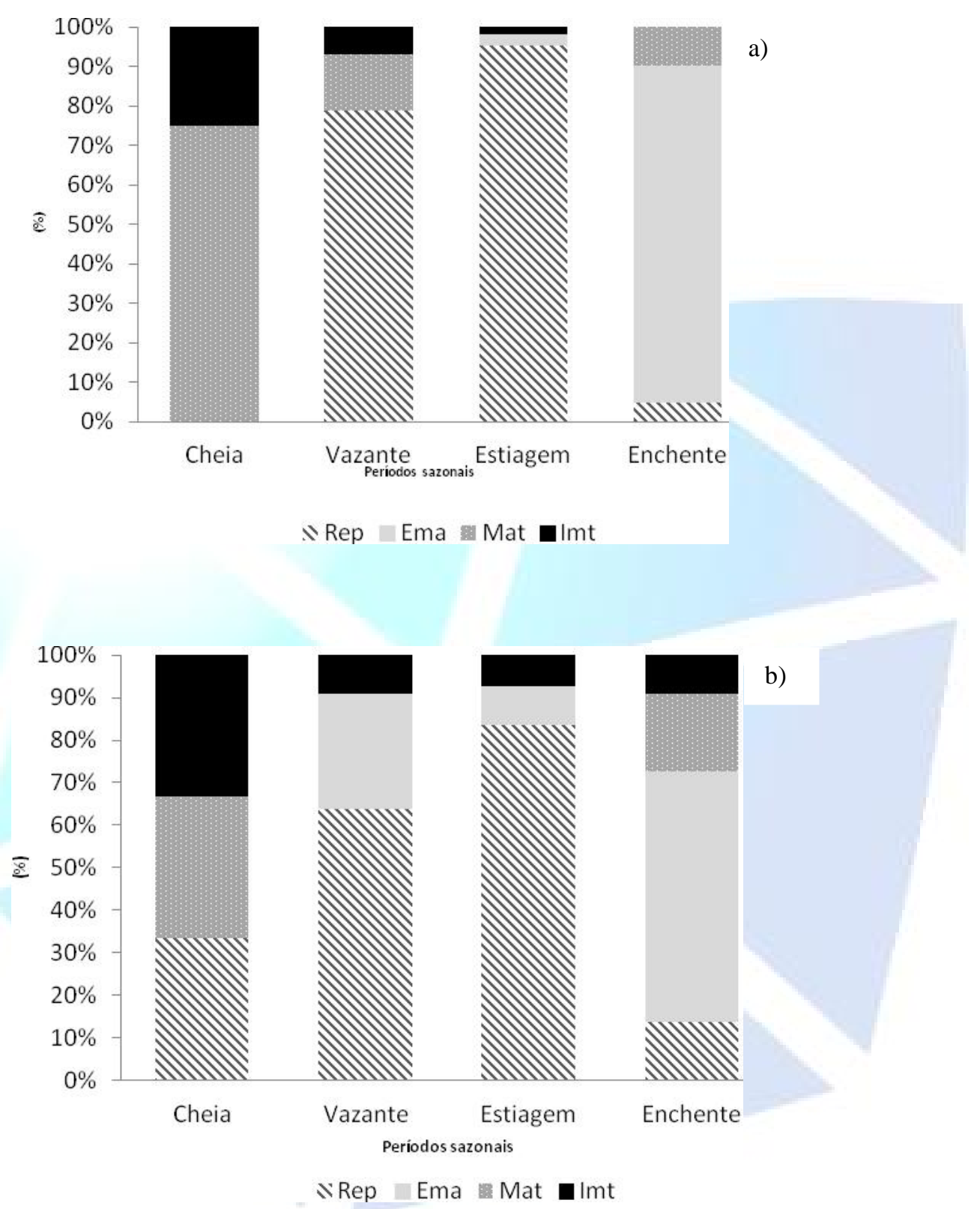

Figura 2. Frequência de Hoplias malabaricus em diferentes estádios de maturação gonadal na Baía Caiçara Superior (BCS) - a, e Baía Caiçara Inferior (BCI) - b, nos diferentes períodos sazonais entre setembro de 2005 a setembro de 2007. Rep= repouso, Ema= em maturação, Mat= maturo e Imt= imaturo. 
H. malabaricus se apresentou com maior abundância de indivíduos em estágio de repouso gonadal no período de estiagem. Em estudos realizados por Araújo-lima e Bittencourt (2001) na Amazônia Central, esta espécie também foi caracterizada como em repouso neste período, o que corrobora com este trabalho.

Esta característica de manter-se em repouso reprodutivo durante as águas baixas do sistema de baías, pode ter ocorrido devido ao fato de que a oferta de alimento, bem como dispersão para acasalamento e reprodução é reduzida.

O período de desova da traíra, no sistema de baías Caiçara, começa no período da enchente, podendo se estender para o período da cheia. O mesmo foi apresentado por Marques (2001), apontando que a época da desova para esta espécie na barragem do rio Gramame-PB, acontece de abril a julho, correspondendo ao período de maior pluviosidade.

Este fato também foi demonstrado por Araújo-Lima e Bittencourt (2001), citando que a desova desta espécie tem início durante as cheias. Paiva (1974) e Barbieri (1989) na Represa do Monjolinho também encontraram resultados semelhantes, sugerindo que devido o aumento da área do sistema, o que amplia a área disponível para a desova e também e proteção dos jovens, com vegetação e "locas", favorece a reprodução e desova de $H$. malabaricus.

A reprodução de fêmeas de $H$. malabaricus, no sistema de baías Caiçara, foi observada a partir de $6,7 \mathrm{~cm}$ e $11,5 \mathrm{~g}$ em fêmeas e nos machos a partir de $15,1 \mathrm{~cm}$ e $39,95 \mathrm{~g}$.

Barbieri (1989) relatou maiores tamanhos para a primeira maturação $(16,7 \mathrm{~cm})$ na Represa de Monjolinho, em relação aos estudos realizados por Caramaschi (1979) na represa do rio Pardo, a primeira maturação é atingida com 13,5 cm de comprimento.

Este autor ainda infere que estímulos ambientais podem dar início a reprodução e desova no ambiente, como por exemplo, a temperatura. Neste estudo, a variação de temperatura no Sistema de Baías Caiçara (Figura 3) apresentou maiores valores nos períodos de enchente e cheia, os quais foram caracterizados como maior dinâmica reprodutiva para $H$. malabaricus. Este resultado sugere que a temperatura pode influenciar os aspectos reprodutivos para esta espécie no ambiente estudado.

A presença de indivíduos jovens e adultos caracteriza o Sistema de Baías Caiçara como adequado para a reprodução com condições favoráveis para o crescimento e a manutenção da população.

Os valores do Índice Gonadossomático para machos e fêmeas de H. malabaricus no Sistema de Baías Caiçara variaram entre os períodos sazonais, ocorrendo índices menores na cheia e vazante e índices maiores no período de estiagem, com destaque na enchente (Figura 3). Este resultado confirma que a atividade reprodutiva desta espécie inicia, principalmente, no período de enchente.

A captura biológica durante o período de cheia pode ter sido prejudicada pelo alto fator de dispersão dos peixes no Pantanal, haja vista que este período há incremento de água no sistema, oferecendo diversidade de habitat e consequentemente dificultando a captura desta espécie.

A temperatura do Sistema de Baías Caiçara associada ao aumento da coluna de água são alguns dos fatores que levam ao desenvolvimento e maturação das gônadas, conforme apontado por Vazzoler (1996). Este autor descreve a influência das variáveis ambientais (temperatura e precipitação) sobre os indivíduos de modo que, as condições na época de desova sejam as mais favoráveis para a prole, pois aumenta as chances de sobrevivência. 


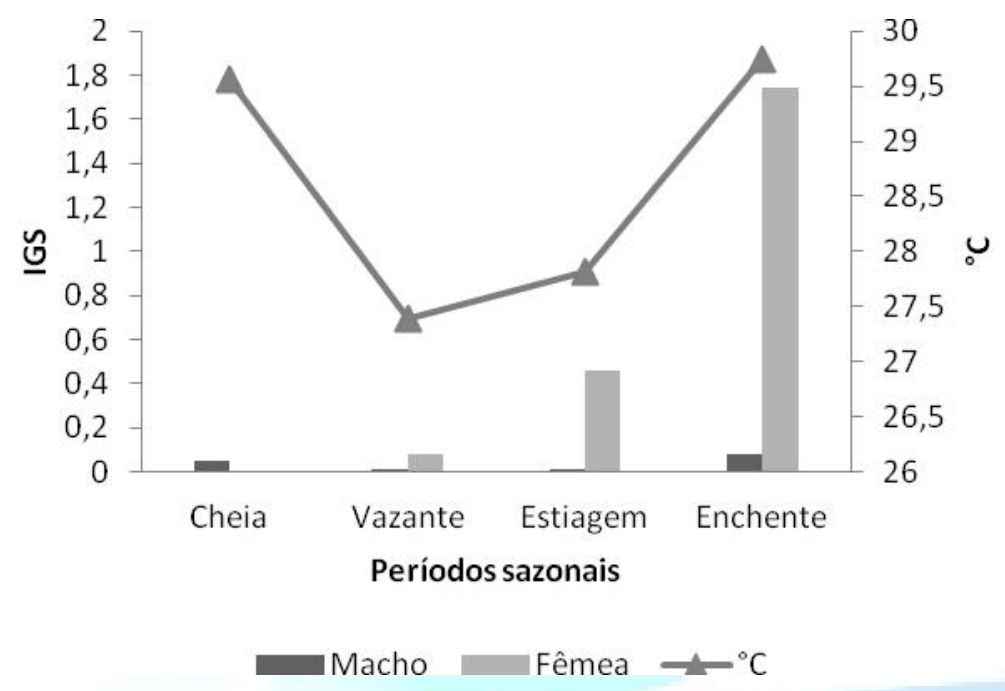

Figura 3. Distribuição por períodos sazonais dos valores do índice gonadossomático e temperatura média no sistema de baías Caiçara entre setembro de 2005 e setembro de 2007.

\section{CONCLUSÕES}

A maior frequência de Hoplias malabaricus ocorreu no período da estiagem, sendo que a menor frequência foi observada no período da cheia devido a dispersão dos animais.

A reprodução desta espécie iniciou no período de enchente e se estendeu até a cheia, época com maior volume de água nas baías, o que por sua vez garante abrigo e alimento para a prole, e com primeira reprodução com tamanhos de 6,7 centímetros.

A dinâmica das águas do Pantanal pode influenciar na reprodução e desova desta espécie, principalmente por alguns aspectos limnológicos, conforme demonstrou o índice gonadossomático e a flutuação nos aspectos reprodutivos.

Dados como este podem auxiliar na caracterização ecológica deste rico e sensível ambiente, gerando dados assistenciais na tomada de decisão pública de uso e manejo ecossistêmico do Pantanal, bem como proteger e resguardar a espécie alvo do estudo.

\section{AGRADECIMENTOS}

Ao grupo de pesquisa ligado ao Laboratório de Ictiologia do Pantanal Norte - LIPAN pela contribuição na elaboração deste estudo, e ao ligado ao Centro de Pesquisa em Limnologia, Biodiversidade e Etnobiologia do Pantanal - CELBE/UNEMAT.

\section{REFERÊNCIAS}

ARAÚJO-LIMA, C.A.R.M.; BITTENCOURT, M.M. A reprodução e o início da vida de Hoplias malabaricus (Erythrinidae: Characiformes) na Amazônia Central. Acta Amazônica, Manaus-AM, v.31, n.4: p.693-697, 2001. 
BARBIERI, G. Dinâmica da reprodução e crescimento de Hoplias malabaricus (Bloch, 1794) (Osteichthyes, Erythrinidae) da represa do Monjolinho, São Paulo/SP. Revista Brasileira de Zoologia, Curitiba-PR, v.6, n.2: p.225-233, 1989.

BIALETZKI, A.; NAKATANI, K.; SANCHES, P.V.; BAUMGARTNER, G. Spatial and temporal distribution of larvae and juveniles of Hoplias aff. Malabaricus (Characiformes, Erythrinidae) in the upper Paraná river floodpalin, Brazil. Brazilian Journal of Biology, São Carlos-SP, v.62, n.2: p.211-222, 2002.

BRITSKI, H.A.; SILIMON, K.Z.; LOPES, B.S. Manual de identificação de peixes do Pantanal. Empresa Brasileira de Pesquisa Agropecuária, Brasília-DF, 2. ed. rev. Ampl. 2007. 227p.

CARAMASCHI, E.M.P. Reprodução e alimentação de Hoplias malabaricus (Bloch, 1794) na Represa do Rio Pardo (Botucatu, SP) (Osteichthyes, Cypriniformes, Erythrinidae). São Carlos, 1979, f. 144. Dissertação ( Mestrado na Universidade Federal de São Carlos) São Carlos, SP. 1979.

CALHEIROS, D.F.; OLIVEIRA, M.D. de. O Rio Paraguai e sua planície de inundação: o Pantanal Mato-grossense. Ciência \& Ambiente, Campinas/SP, v.41: p.113-130, 2010.

FOWLER, H.W. Os peixes de água doce do Brasil. Arquivos de Zoologia do Estado de São Paulo, São Paulo-SP, v.6: p.362-364, 1950.

JUNK, W.J. The flood pulse concept of large rivers: learning from the tropics. Archiv für Hydrobiologie. Supplementband. Large rivers, Stuttgart-Schweizerbart, v.11, n.3: p.261-280, 1999.

MARQUEZ, D.K.S.; GURGEL, H.C.B.; LUCENA, I. Época de reprodução de Hoplias malabaricus Bloch, 1794 (Osteichthyes, Erythrinidae) da barragem do rio Gramame, Alhandra, Paraíba, Brasil. Revista Brasileira de Zoociências, Juiz de Fora-MG, v.3, n.1: p.61-67, 2001.

MUNIZ, C. C. Avaliação do pulso de inundação sobre a riqueza e biodiversidade de peixes em ambiente inundável no sistema de baías Caiçara, porção norte do Pantanal Matogrossense, Alto Paraguai. São Carlos, 2010. f. 82. Tese de doutorado (Doutorado na Universidade Federal de São Carlos) São Carlos-SP, 2010.

PAIVA, M. P. Crescimento, alimentação e reprodução da traíra, Hoplias malabaricus (Bloch), no nordeste brasileiro. Fortaleza, 1974.f. 32. Tese de Doutourado (Doutroado na Universidade Federal do Ceará) Fortaleza-CE. 1974.

RESENDE, E.K.; PEREIRA, R.A.C.; ALMEIDA, V.L.L.; SILVA, A.G. Alimentação de peixes carnívoros da planície inundável do rio Miranda, Pantanal, Mato Grosso do Sul, Brasil. Corumbá, MS: EMBRAPA-CPAP, Boletim de Pesquisa, Corumbá-MS, n.3, 1996. 36 p.

TORRES, L.M.; ZAMBIAZI, R.C.; CHIATTONE, P.V.; FONSECA, T.P.; COSTA, C.S. Composição em ácidos graxos de traíra (Hoplias malabaricus) e pintadinho (sem classificação) provenientes da Região Sul do Rio Grande do Sul e Índia Morta no Uruguai. Semina: Ciências Agrárias, Londrina, v.33, n.3, p.1047-1058, 2012. 
UIEDA, V.S. Ocorrência e Distribuição dos Peixes los hum riacho de Água Doce. Revista Brasileira de Biologia, São Carlos-SP, v.44, n.2: p.203-213,1984.

VAZZOLER, A.E.A.M. Biologia da reprodução de peixes teleósteos: teoria e prática. EDUEM SBI, São Paulo, 1996, 169p.

VAZZOLER, A.E.A.M.; MENEZES, N.A. Síntese de conhecimentos sobre o comportamento reprodutivo dos Characiformes da América do Sul (Teleostei, Ostariphysi). Revista Brasileira de Biologia, São Carlos-SP, v.52: p.627-640, 1992.

WINEMILLER, K.O. Ontogenetic diet shifts and resource partioning among piscivorous fishes in the Venezuelan ilanos. Environment Biology of Fisheries, Netherlands, v.26: p.177-199, 1989. 